\title{
Integrating Constructivist Learning Environments (CLEs) in Designing a Multimedia Learning Application for Cyber-Bullying Intervention
}

\author{
Nadia Abdul Wahab ${ }^{1 *}$, Aznoora Osman ${ }^{2}$, Norfiza Ibrahim ${ }^{3}$, Siti Sarah Md Ilyas ${ }^{4}$ \\ 1,2,3,4 Faculty of Computer and Mathematical Sciences, \\ Universiti Technologi MARA, Perlis Branch, Arau Campus, 02600 Arau, Perlis, Malaysia \\ Corresponding author: *nadiawahab@uitm.edu.my \\ Received Date: 20 August 2021 \\ Accepted Date: 31 August 2021 \\ Published Date: 13 September 2021
}

\section{HIGHLIGHTS}

- Constructivist Learning Design Environments (CLEs) is being integrated in designing a multimedia learning application for cyber-bullying Intervention.

- The multimedia learning app has the capability to increase adolescents' knowledge and awareness towards cyber-bullying.

- Constructivism and CLEs promotes active learning and develop advanced skills such as critical thinking, analysis, evaluation, and creation.

\begin{abstract}
Constructivism is a learning theory that emphasizes learners' intervention through self-guided exploration, reflection, and evaluation. This study discusses on the integration of the Constructivist Learning Environments (CLEs) in designing a multimedia learning application for cyber-bullying intervention among adolescents. The application has been evaluated using Alpha Testing and Beta Testing technique to ensure its quality. From this evaluation, the researcher was also able to identify weaknesses or problems associated with the usage of the application, from the viewpoint of the content and multimedia expert and also the target user group which are the adolescents. By integrating CLEs, it is expected that knowledge and awareness is constructed by the learners as they reconcile new information with past experiences, analyze various source materials, and work collaboratively with others. As CLEs stimulates active learning, it is hoped that leaners will develop advanced skills such as critical thinking, analysis, evaluation, and creation. As CLEs promotes diverse viewpoints, it encourages students to reflect, evaluate their work, and identify intermediary skills to acquire based on their needs. It is also expected that the development of the multimedia app in this study will contributed to an increase in the number of computer-based applications intended to expose adolescents to the issue of cyber-bullying, which is still under-developed, particularly in the context of adolescents in Malaysia.
\end{abstract}

Keywords: Constructivism, Constructivist Learning Environments (CLEs), Active Learning, Cyberbullying, Alpha Testing, Beta Testing

\section{INTRODUCTION}

In recent years, the use of social media, mass media, digital-based social media, e-mail, instant messaging, social network sites, chat rooms, video and photograph sharing applications, and online multiplayer (9) $(\Theta \Theta()$ Copyright $\subseteq 2021$ UiTM Press. This is an open access article under the CC BY-NC-SA (https://creativecommons.org/licenses/by-nc-sa/4.0//) 
computer games have started to affect our lives more and more (Santrock, 2012). The desire to keep and share the information produced, to access information easily, and to take advantage of the wide-spread use of Internet technologies has turned cyber-victimization and cyber bullying on the Internet into a significant problem among the adolescents (Ouytsel, Walrave, \& Vandebosch, 2015). Cyber bullying can be defined as "aggressive and intentional acts against those who cannot defend themselves via electronic forms of communication by a group or an individual (Patchin \& Hinduja, 2017). Cyber bullying is more dangerous than bullying in real life, in that it can reach a wider audience. According to recent studies conducted worldwide, approximately $25.5-67.5 \%$ of adolescents are affected by cyberbullying (Patchin \& Hinduja, 2017).

Most cyberbullying cases go unreported and there is a dearth of research on the problem in most countries with most of the existing literature devoted to specific groups such as schoolchildren and the youth (Soni \& Singh, 2018). Several surveys have reported the rising rate of cyberbullying in Malaysia. The findings of an empirical investigation on Malaysian children's internet use revealed that one in every five children that go online has become the target of cyberbullying at least once and that $30 \%$ of young girls have been sexually harassed in an online chatroom (Yusuf et al., 2018). An international survey involving 1,896 teenage Malaysians aged 12 to 18 years revealed that $40 \%$ of the participants encountered cyberbullying, nearly a half (47\%) of them sought their parents' advice when they got stuck online while $40 \%$ of them were addicted to online peer pressurizing such as using hurtful messages to harass someone (Yusuf et al., 2018).

Adolescents generally lack the critical capacity to question the credibility of the online content and relationships that they build online (UNICEF - The State of the World's Children: Children in a Digital World, 2017). Although cyber- bullying has been reported to be very common (Eroglu et al., 2015), only $20 \%$ of parents supervise Internet use among their children. As noted in the recent WHO report, parents need to be actively involved with protecting and supervising their children's use of the Internet. Active engagement between parents and their children enable on safe and productive use of the Internet and reduction of the negative risks (Solecki \& Fay-Hiller, 2015).

Given that cyber-bullying has become more serious lately, steps should be taken to ensure that this threat is curtailed (Campbell \& Bauman, 2018). Some schools currently use small group discussions, large school assemblies, or lecture workshops to address the problem of cyber-bullying with students and these methods are often ineffective (Beale and Hall, 2007; Diamanduros et. al, 2008). Other than the conventional methods, other initiatives that could be taken include developing a Multimedia App that would be able to assist adolescents in increasing their knowledge and awareness on cyber-bullying.

Development of an interactive Multimedia App that comes with attractive graphics, audio and animation have great potential in attracting the interest of adolescents in gaining a deeper understanding of this issue. In developing the Multimedia App for the purpose of this research, it was of utmost importance for the researcher to understand and apply the certain theory or principle such as constructivism so that the app that is developed is more effective and helpful in increasing learning outcome. Constructivism promotes active learning and at the same time has the capability to foster the problem-solving and conceptual development of the learners.

This paper starts with the discussion of Constructivist Learning Environment (CLEs), followed by the explanation on how the design process has been accomplished by integrating CLEs. The subsequent section elaborate on the evaluation process of the multimedia application. This section focuses on two type of evaluation techniques which are Alpha Testing and Beta Testing. The last section concludes all the sections that has been discussed throughout this paper. 


\section{Constructivist Learning Environments (CLEs)}

The principles of constructivism emphasize that learning is an active process. Woolfolk (1993) defined the learning process in constructivist context as a process where the minds of learners receive input from the external world to determine what they will learn. According to Jonassen (1991), learning is considered as active mental work, not passive reception of teaching. Because learners have unique sets of experience with the world and the beliefs about them, they might think about external reality in different ways during the learning process.

From the perspective of the constructivist, learning is determined by the learners' existing knowledge, the social context and problems that will be solved while instruction means preparing learners in a collaborative situation where they have the capability and opportunity to construct specific understanding by combining existing information from various sources (Ertmer and Newby, 1993).Constructivist conceptions of learning, assume that knowledge is individually constructed and socially co-constructed by learners based on their interpretations of experiences in the world (Jonassen, 1991). Since knowledge cannot be transmitted, instruction should consists of experiences that provide interpretable experiences and facilitate knowledge construction (Jonassen, 1991).

Jonassen (1999) suggested that the constructivist learning environment (CLEs) design must include elements such as exposure and manipulation of problems, relevant experience, the reach for sources of information, cognitive tools as well as social and contextual support. According to Jonassen (1999), this form of design is the strategy that supports learners' achievement.

The model for designing CLEs as shown in Figure 1 illustrates their essential components. According to Jonassen (1999), the model conceives of a problem, question, or project as the focus of the environment, with various interpretative and intellectual support systems surrounding it. The goal of the learner is to interpret and solve the problem or complete the project. Related cases and information resources support understanding of the problem and suggest possible solutions; cognitive tools help learners to interpret and manipulate aspects of the problem; conversation or collaboration tools enable communities of learners to negotiate and co-construct meaning for the problem; and social/contextual support systems help users to implement the CLE (Jonassen, 1999).

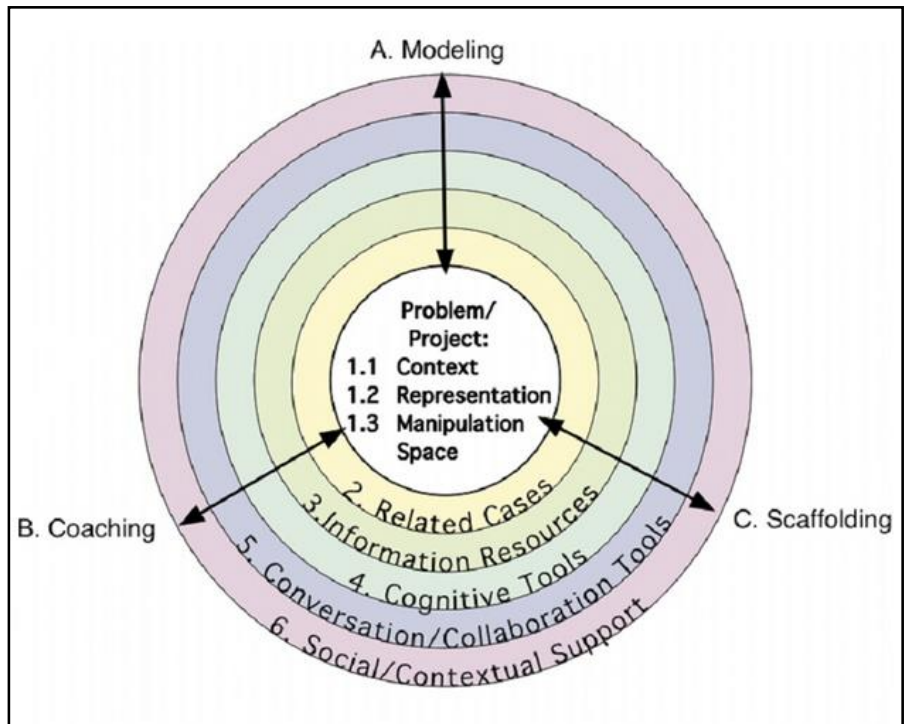

Figure 1: Jonassen's Model for Designing Constructivist Learning Environment 


\section{DESINING THE MULTIMEDIA APPLICATION}

Constructivist Learning Environments (CLEs) which was developed by Jonassen (1999) is based on problem-based learning whereby the learners need to solve the problem by exploring all knowledge components such as (i) problems, (ii) related cases, (iii) information resources, (iv) cognitive tools, (v) conversation and collaborative tools and (vi) social contextual support. In designing the multimedia application, five out of six components of CLEs have been adapted to ensure that this Multimedia App will foster the problem-solving and conceptual development of the learners.

\section{Component 1: Problem}

The problem is presented to learners in the form of animation at the early stages of the learning process to attract their interest. According to Jonassen (1999), the problem should be interesting, relevant and engaging in order to promote learner ownership. Therefore in this section, the researcher has introduced a situation whereby an adolescent has received a message with elements of cyber-bullying on social network. Following this, another teenager who is the pedagogical agent in this Multimedia App will ask questions about whether or not learners have ever experienced or witnessed events similar to the one highlighted a while ago, and what action should be taken. Figure 2 shows how the problem is presented at the introduction of the app.

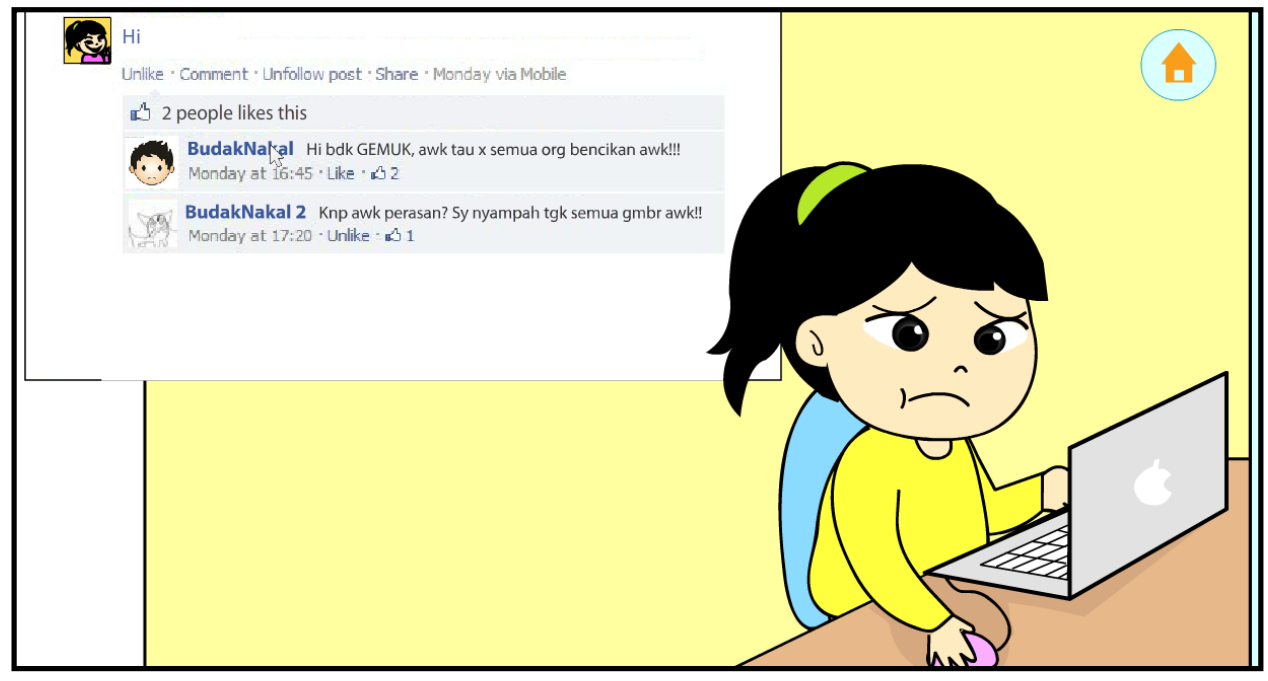

Figure 2: Screenshot of the Introduction Screen

\section{Component 2: Related Cases}

The related cases are highlighted in this app in animation form and reinforcement activity. According to Jonassen (1999), related cases or worked examples should be given to learners to enable case-based reasoning and enhance cognitive flexibility. In this Multimedia App, related cases show examples of frequently-occurring cyber-bullying behaviour, the consequences of cyber-bullying as well as action that must be taken to overcome this problem. Learners' memory scaffold will be enhanced by presenting examples which have similarities in terms of problems, context, situation and outcomes. Learners will make comparisons between the related cases highlighted and the problems they face in finding the best way to overcome the problem. Figure 3 and 4 shows examples of frequently-occurring cyber-bullying behaviours (e.g. harassment and flaming) as related cases of this Multimedia App. 


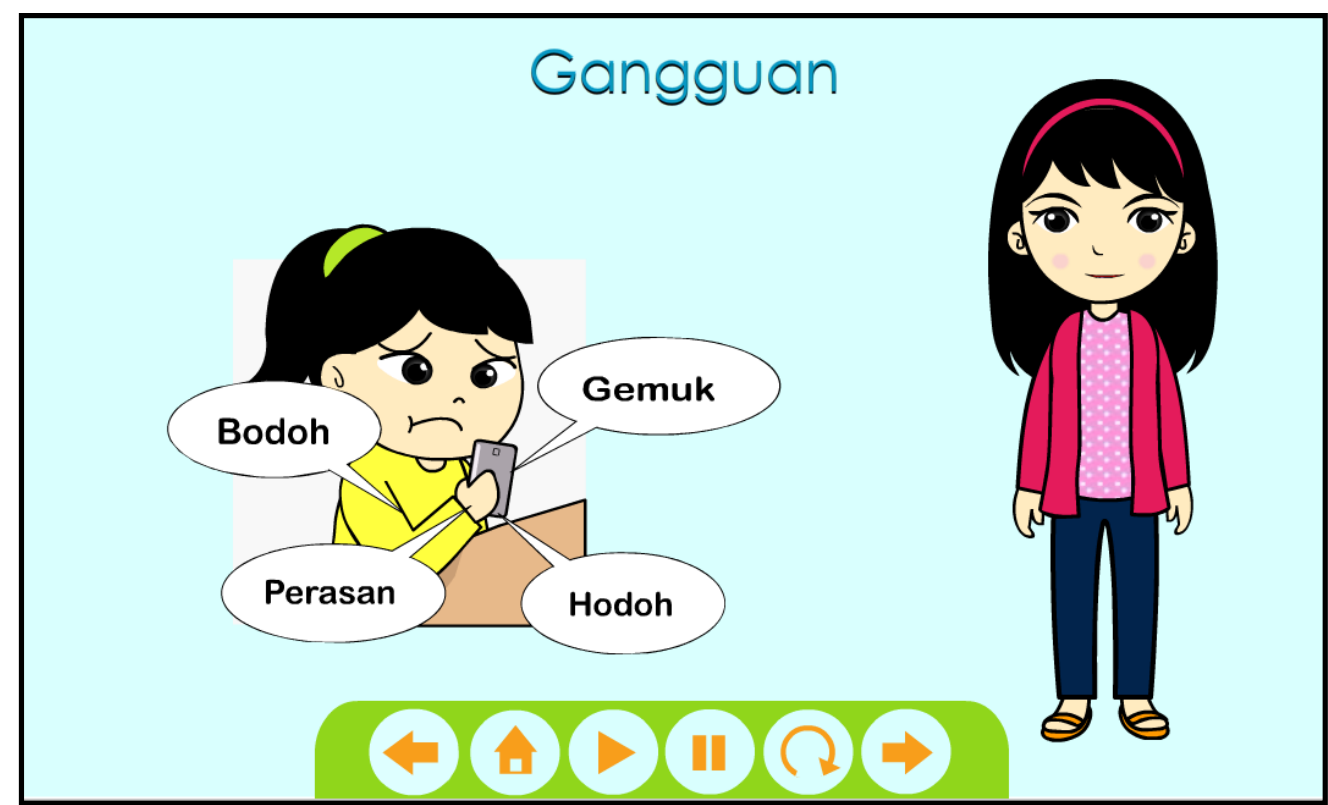

Figure 3: Screenshot of an Example of Frequently-Occurring Cyber-Bullying Behaviour (Harassment)

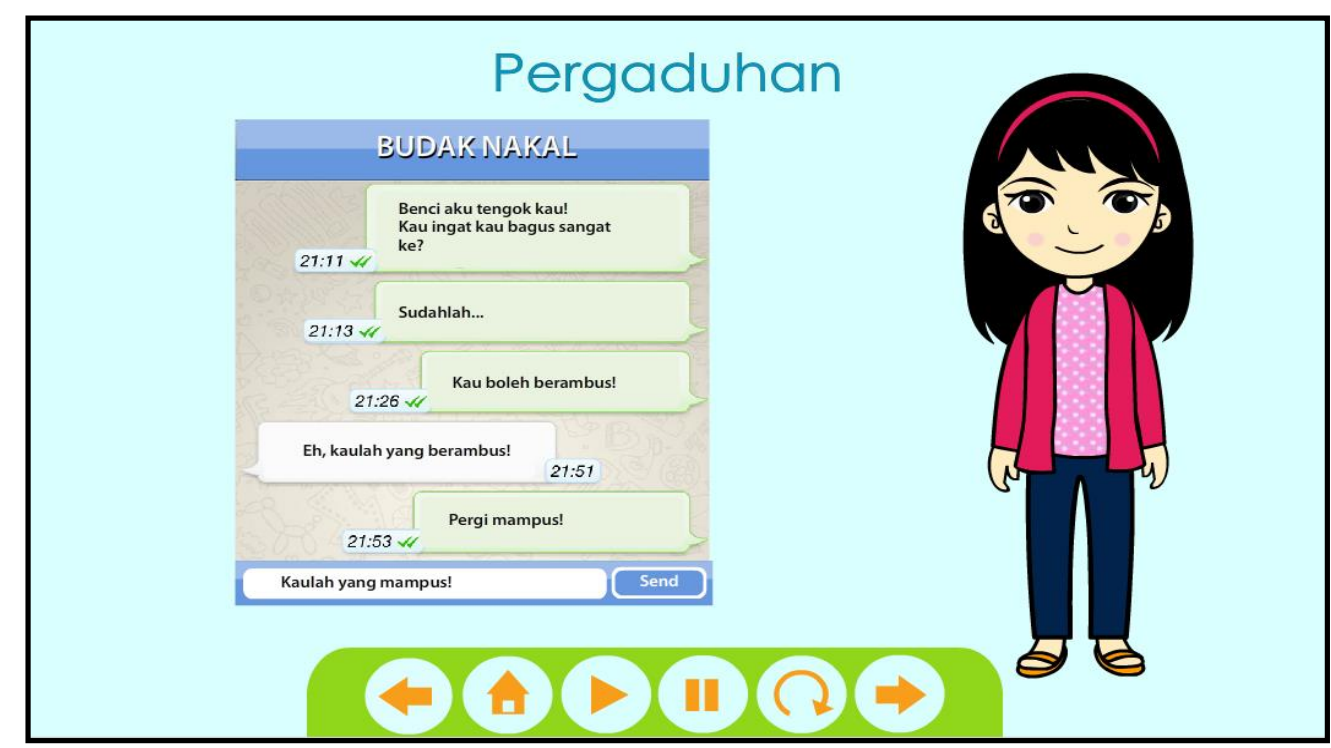

Figure 4: Screenshot of an Example of Frequently-Occurring Cyber-Bullying Behaviour (Flaming)

\section{Component 3: Information Resources}

Information resources are also presented to learners in this app. Jonassen (1999) suggested that the developer provides learner-selectable information just-in-time to foster problem solving and conceptual development. For that, learners are free to select whichever module in this app to learn first according to her or his aptitude. Learners can also return to the modules that they have learnt according to necessity. Figure 5 shows the main menu consisting of modules that have been prepared in this app, which can be selected by users. The menus consist of the (i) definition of cyber-bullying, (ii) the danger of cyber-bullying, (iii) how to overcome cyber-bullying and (iv) activities. 


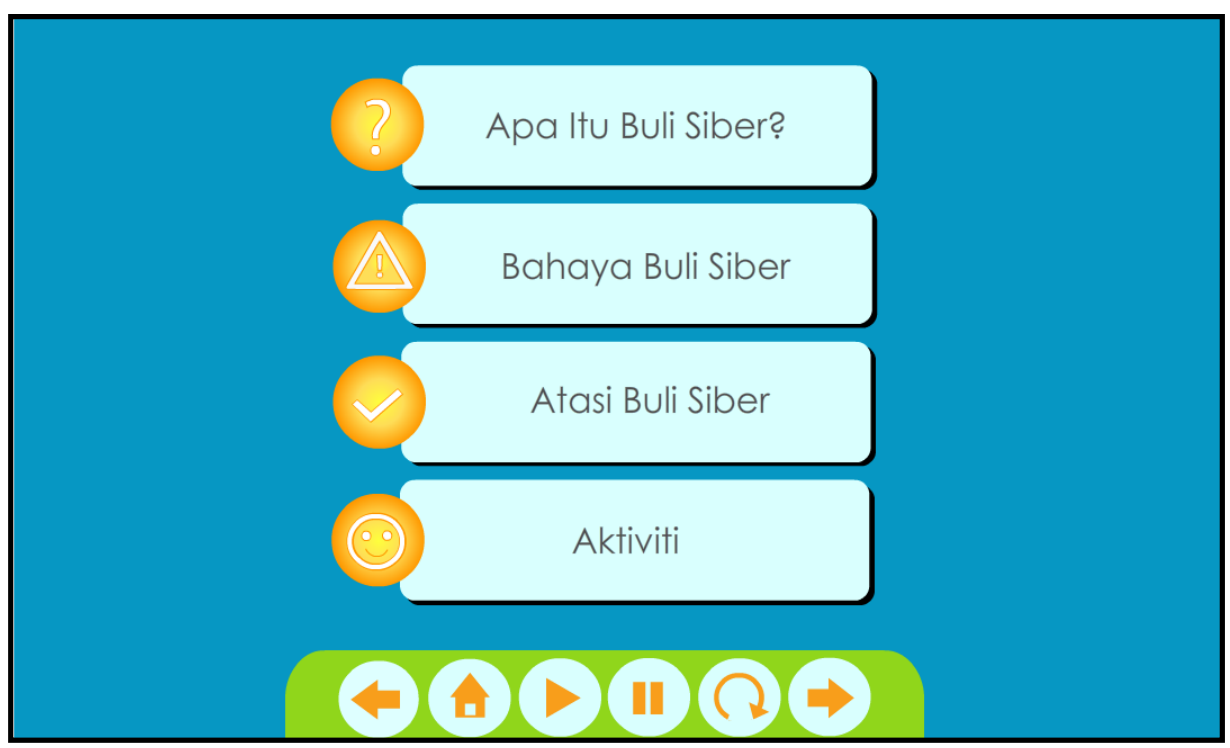

Figure 5: Screenshot of Main Menu of the Multimedia App

\section{Component 4: Cognitive Tools}

The cognitive tools are important component that could scaffold required skills, including problemrepresentation tools, knowledge-modelling tools, performance-support tools, and information-gathering tools (Jonassen, 1999). Kommers, et. al (1992) defined cognitive tools as generalizable computer tools that could be used to engage and facilitate cognitive processing. In this research, the content of the Multimedia App act as the problem-representation tools as they help learners to visualize and construct the mental model about how the objects behave and interact. Figure 6,7,and 8 shows some of the screenshots based on the contents of the Multimedia App. Besides that, this also acts as knowledge modelling tools whereby it helps the learners to make their understanding of the problem explicit.

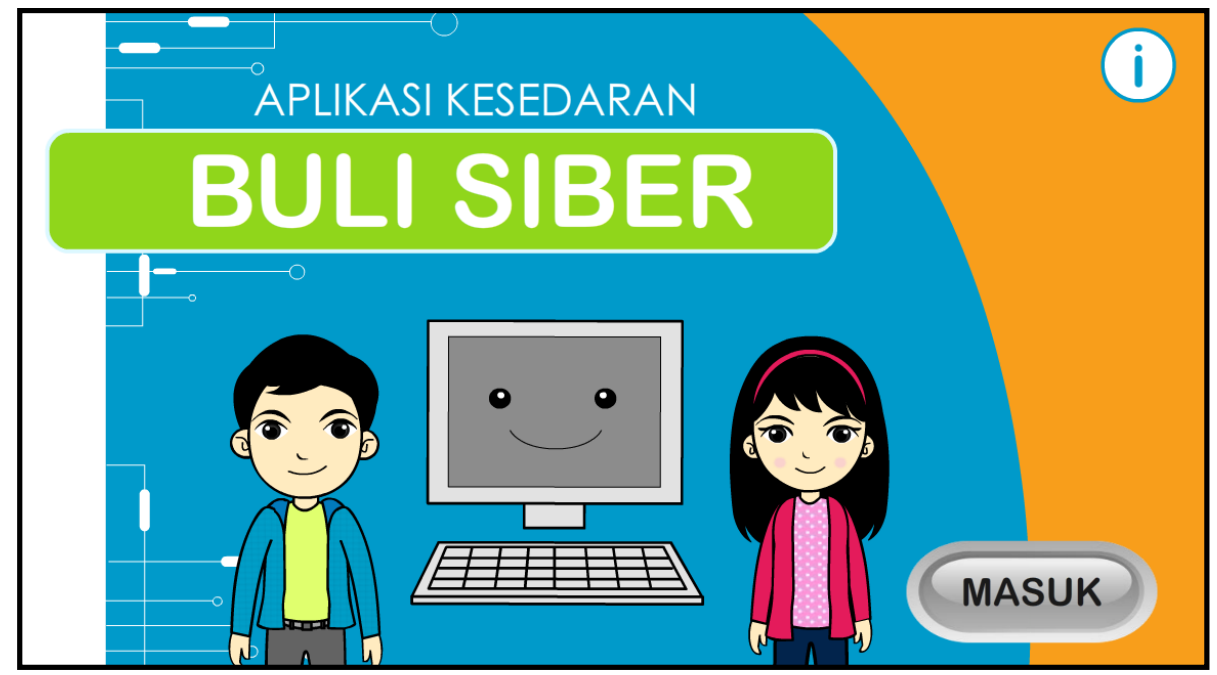

Figure 6: Screenshot of Main Menu from the Multimedia App 


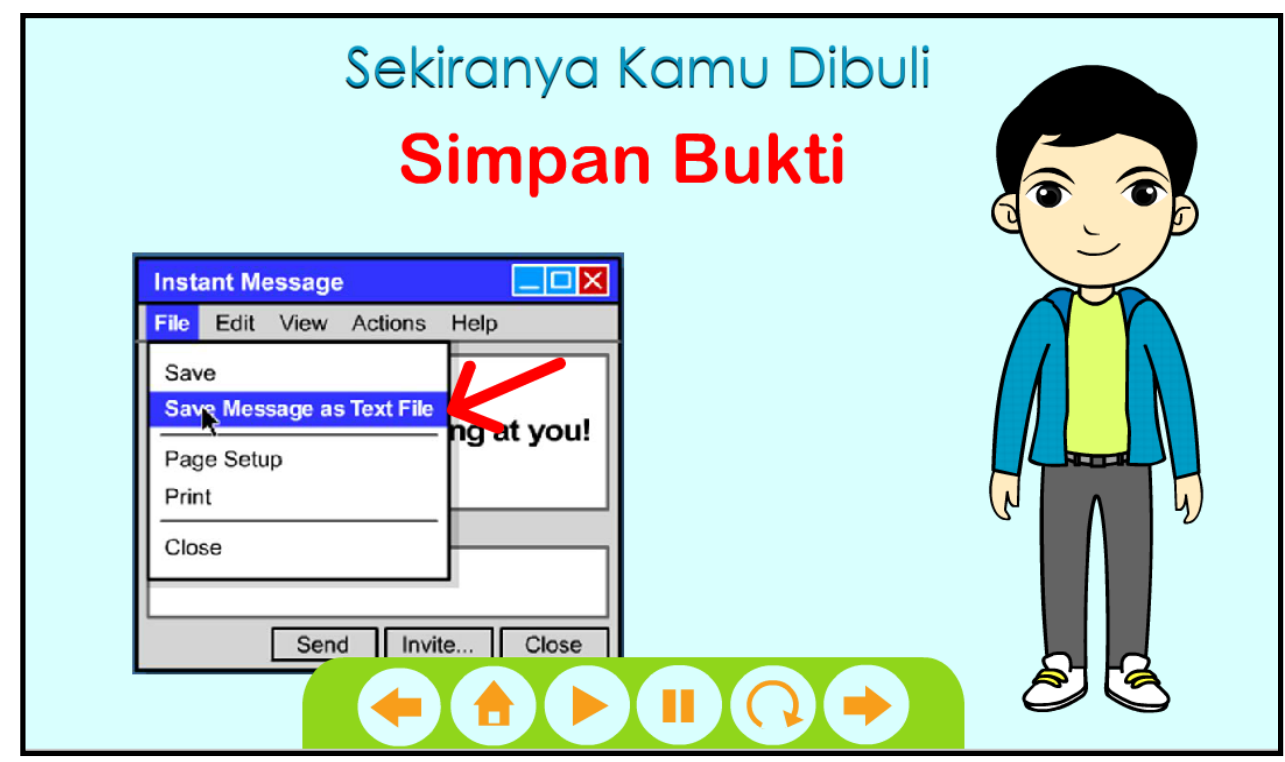

Figure 7: Screenshot from the Multimedia App

\section{Soalan 10 \\ Berikut adalah status-status yang tersiar di facebook. Sila like pada status dirasakan sesuai.}

\section{facebook}

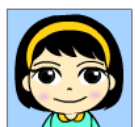

Amira Amir

Gambar terbaru kucing saya.. Cute kan?

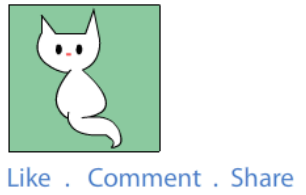

Bob Bob

Aku benci cerita korea.. Siapa minat cerita korea mmg POYO.

Like . Comment . Share

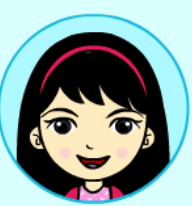

Figure 8: Screenshot of the Reinforcement Activity

\section{Component 5: Social Contextual Support}

Social contextual support is also provided for learners using this app. For this app, there is a support screen listing hyperlinks from websites related to cyber-bullying topics that learners can access to acquire additional information such as cyber-bullying help-line, research centre, resource centre and more. 


\section{EVALUATION}

\section{Alpha Testing}

According to Alessi and Trollip (2001), alpha testing is the quality test on multimedia applications which have been developed with the intention of identifying and solving problems that have arisen. The experts involved in this testing are content experts and a multimedia expert. A senior lecturer with a $\mathrm{PhD}$ qualification from a public university who is also an expert in cyber-bullying and a school counsellor whom possesses a master degree in counselling involved in the alpha testing as the content expert. The content experts were requested to evaluate the Multimedia App by filling up an evaluation form adapted from Roblyer, Edwards, \& Havriluk (1997).

The multimedia expert, who is a senior lecturer from a public university, was involved in this stage of alpha testing. His task was to evaluate the usability of this Multimedia App. After evaluating the app, the multimedia expert was requested to fill up the heuristic evaluation form which was adapted from Nielsen (1994).

From this alpha testing, it can be concluded that the content developed has met the requirement of the app which is to provide knowledge and awareness about cyber-bullying to adolescents. The content experts were also of the opinion that the examples provided in this app are relevant to the situation of adolescents in Malaysia. The content experts identified several minor flaws such as wrong spelling and inaccurate terminology. In addition, the content experts suggested the researcher to increase the number of screens to provide more information on coping strategy of cyber-bullying.

Additionally, the multimedia expert involved in this testing was of the opinion that the app that has been developed is good and has met the usability requirement in a Multimedia App. The multimedia expert, however, gave several suggestions like adding the 'replay' button so that every screen can be re-played by the user. In addition, the expert also suggested that the researcher used fonts that are consistent in size and colour throughout the app. All comments from the experts involved have been recorded with the intention of improving the quality of this Multimedia App. All amendments based on the comments of each expert involved were implemented before the beta testing was carried out on the target group, namely the adolescents.

\section{Beta Testing}

After carrying out the improvements on the app based on the comments from the experts, the researcher executed the second level of evaluation known as beta testing. This test was carried out on users, namely adolescents with backgrounds similar to those of the target population. According to Alessi and Trollip (2001), the purpose of beta testing is to understand the level of usefulness and usability of an application that has been developed. Usefulness refers to how useful an application that has been developed in supporting the learning process. Usability, on the other hand, is related to the operation of the application technically, that encompasses two aspects, namely interface and interaction. Through this test, the effectiveness of the improvements carried out after the alpha testing, can be determined. Other than that, the researcher was also able to identify any weakness or problem associated with the usage of the software, from the viewpoint of the target user group, the adolescents.

\section{One-to-one Evaluation}

A total of three adolescents comprising of secondary school students were involved in this evaluation process. Each student would be with the researcher individually to make the evaluation on the Multimedia 
App that has been developed. Participants were requested to explore the app under the supervision of the researcher. The researcher observes without interrupting the participants. Notes were taken on the change in participants' behaviour, facial expression and body language in order to understand their reaction towards the app.

\section{Small Group Evaluation}

Following that, participants were interviewed for detailed feedback on the app that has been developed, in particular on its content and operation. The results of the one-to-one survey found that all three participants were satisfied with the software they had explored. Positive responses were received from these participants, especially for content, presentation, animation and reinforcement activity that attracted their attention.

The second stage of beta testing is small group evaluation; comprising 15 adolescents from a secondary school with backgrounds similar to those of the target population. All the participants were given the opportunity to use the Multimedia App that has been developed and they were then asked to make an evaluation on the app in terms of usability by filling in the questionnaire. This questionnaire used the likertscale format with 5 responses. Scores range from 1 to 5 whereby 5 represents the strongly agree statement while 1 represents the strongly do not agree statement. The findings show that the Multimedia App that has been developed fulfilled the usability aspect, for example it is easy to use, and it has interesting interface design, appropriate choice of colour and animation quality, as well as good graphics and audio. The results of this evaluation also found that no programming or technical errors undermined the use of this app.

\section{CONCLUSION}

In developing the Multimedia App for the purpose of this research, the researchers had apply the constructivism theory to ensure that the app that is developed is more effective in increasing knowledge and awareness regarding cyber-bullying among adolescents. As constructivism promotes active learning, it has the capability to foster the problem-solving and conceptual development of the learners. By integrating CLEs, it is expected that knowledge and awareness is constructed by the learners as they reconcile new information with past experiences, analyze various source materials, and work collaboratively with others. As CLEs stimulates active learning, it is hoped that leaners will develop advanced skills such as critical thinking, analysis, evaluation, and creation. Furthermore, the development of the multimedia app in this study has contributed to the increase the number of computer-based applications intended to expose adolescents to the issue of cyber-bullying, which is still under-developed, particularly in the context of adolescents in Malaysia.

\section{REFERENCES}

Alessi, S. M., \& Trollip, S. R. (2001). Multimedia for learning: Methods and development (3rd ed.). Boston, MA: Allyn \& Bacon.

Beale, A. V., \& Hall, K. R. (2007). Cyberbullying: What school administrators (and parents) can do. The Clearing House: A Journal of Educational Strategies, Issues and Ideas, 81(1), 8-12. 
Campbell, M., \& Bauman, S. (Eds.). (2018). Reducing cyberbullying in schools: International evidencebased best practices. Academic Press.

Eroglu, Y., Aktepe, E., Akbaba, S., Isik, A., \& Özkorumak, E. (2015). The investigation of prevalence and risk factors associated with cyber bullying and victimization. Egitim ve Bilim, 40(177).

Ertmer, P. A., \& Newby, T. J. (1993). Behaviorism, cognitivism, constructivism: Comparing critical features from an instructional design perspective. Performance improvement quarterly, 6(4), 50-72.

Jonassen, D. (1991). Objectivism versus constructivism: Do we need a new philosophical paradigm? Educational technology research and development, 39(3), 5-14.

Jonassen, D. (1999). Designing constructivist learning environments. Instructional design theories and models: A new paradigm of instructional theory, 2, 215-239.

Nielsen, J. (1994). Heuristic evaluation. Usability Inspection Methods, 24, 413.

Ouytsel, J., Walrave, M., \& Vandebosch, H. (2015). Correlates of cyberbullying and how school nurses can respond. NASN School Nurse, 30(3), 162-170.

Patchin, J. W., \& Hinduja, S. (2017). Digital self-harm among adolescents. Journal of Adolescent Health, 61(6), 761-766.

Roblyer, M. D., Edwards, J., \& Havriluk, M. J. (1997). Integrating educational technology into teaching. Columbus, OH: Prentice Hall.

Santrock, J. W. (2012). In D. M. Siyez (Ed.), Adolescence (pp. 1) (14st ed.). Ankara: Nobel Academic (Translation editor).

Solecki, S. and Fay-Hillier, T., 2015. The Toll of Too Much Technology on Teens' Mental Health. Journal of pediatric nursing, 30(6), pp.933-936.

Soni, D., \& Singh, V. K. (2018). See no evil, hear no evil: Audio-visual-textual cyberbullying detection. Proceedings of the ACM on Human-Computer Interaction, 2(CSCW), 1-26.

Yusuf, S., Hassan, M. S. H., \& Ibrahim, A. M. (2018). Cyberbullying among Malaysian children based on research evidence. In M. Khosrow-Pour (Ed.), Encyclopedia of information science and technology (4th ed.) (pp. 1704-1722). Hershey, USA: IGI Global. 